\title{
Performance of automated activity monitoring systems used in combination with timed artificial insemination compared to timed artificial insemination only in early lactation in dairy cows
}

\author{
J. Denis-Robichaud, ${ }^{*}$ R. L. A. Cerri,† A. Jones-Bitton, ${ }^{*}$ and S. J. LeBlanc ${ }^{* 1}$ \\ *Department of Population Medicine, University of Guelph, Guelph, Ontario N1G 2W1, Canada \\ †Applied Animal Biology, Faculty of Land and Food Systems, University of British Columbia, Vancouver, BC V6T 1Z4, Canada
}

\begin{abstract}
Identifying cows in estrus remains a challenge on dairy cattle farms, and tools and technologies have been developed and used to complement or replace visual detection of estrus. Automated activity monitoring (AAM) systems and timed artificial insemination (TAI) are technologies available to dairy farmers, but many factors can influence their relative performance. The objective of the present study was to compare reproductive performance of cows managed with an AAM system combined with TAI, or with a TAI program (Double Ovsynch) for insemination before 88 DIM. From April 2014 to April 2015, 998 cows from 2 herds were randomly assigned either to be inseminated at $85 \pm 3$ DIM exclusively using the Double Ovsynch protocol for TAI, or to be inseminated based on estrus detection by AAM without hormonal intervention between 50 and 75 DIM; if no alarm was detected by 75 DIM, cows were inseminated following the single Ovsynch protocol (AAM + Ovsynch). The herds used different AAM systems. Parity, hyperketonemia at wk 1 and 2 postpartum (PP), purulent vaginal discharge at wk $5 \mathrm{PP}$, body condition score at wk $7 \mathrm{PP}$, and anovulation to wk $9 \mathrm{PP}$ were recorded. These health indicators did not significantly differ between treatments, but did between herds. The effect of treatment on pregnancy at first insemination and by 88 DIM were assessed using logistic regression models. Time to pregnancy was assessed using survival analysis. Results are reported from intention-to-treat analyses. Treatment did not affect pregnancy at first insemination or pregnancy by 88 DIM, but we found significant interactions between treatment and herd for both outcomes. In herd 2, marginal mean pregnancy at first AI was greater with Double Ovsynch (38\%) than
\end{abstract}

Received November 4, 2016.

Accepted August 28, 2017.

${ }^{1}$ Corresponding author: sleblanc@uoguelph.ca
AAM + Ovsynch (31\%), but no difference was observed in herd 1 (Double Ovsynch $=31 \%$; AAM + Ovsynch $=34 \%$ ). By 88 DIM, a smaller proportion of cows in herd 1 were pregnant in Double Ovsynch $(31 \%)$ than AAM + Ovsynch (49\%), but there was no difference in herd 2 (Double Ovsynch $=38 \%$; AAM + Ovsynch $=$ $38 \%)$. We observed a treatment by herd interaction for median (95\% confidence interval) time to pregnancy, which were, in herd 1, 110 (106 to 129) and 98 (88 to 113) d, and, in herd 2, 126 (113 to 139) and 116 (105 to 131) d for the Double Ovsynch and AAM + Ovsynch treatments, respectively. The relative performance of AAM-based reproductive management compared with TAI only is likely influenced by herd-specific variables, in particular related to insemination rate when estrus detection is employed.

Key words: automated activity monitors, Double Ovsynch, estrus, reproductive management

\section{INTRODUCTION}

Reproductive performance in dairy cows has a large effect on herd profitability and efficiency of production. Prolonged postpartum anovulation is a challenge, as it is associated with extended time to first insemination and decreased conception risk (Gümen et al., 2003; Walsh et al., 2007), and typically affects $20 \%$ of cows in dairy herds (Walsh et al., 2007; Dubuc and Denis-Robichaud, 2017). For estrous cycling cows, the challenge resides in the ability to detect cows in estrus because of low frequency and duration of primary signs of estrus (Lopez et al., 2004; Madureira et al., 2015), or due to lack of time and visual detection skills on part of the herd personnel (Denis-Robichaud, 2016). In the last $20 \mathrm{yr}$, tools and technologies have been developed and implemented to overcome these hurdles. For example, the use of reproductive hormones to increase insemination rate is now common on dairy farms in North America (Caraviello et al., 2006; Ferguson and Skidmore, 2013), and timed artificial insemination (TAI) programs have been refined to increase the probability 
of pregnancy per AI (P/AI). Many such synchronization programs are available, and recent studies suggest the Double Ovsynch protocol offers good performance for first TAI, especially in primiparous cows (Souza et al., 2008; Herlihy et al., 2012).

The first reported use of automated activity monitoring (AAM) systems was 4 decades ago (Kiddy, 1977). Their use has since been refined (At-Taras and Spahr, 2001; Firk et al., 2002; Løvendahl and Chagunda, 2010), and their performance, when used in combination with TAI, has been, on average, comparable to TAI in recent clinical trials (Neves et al., 2012; Fricke et al., 2014; Dolecheck et al., 2016). For first AI, AAM systems were used to identify cows in estrus between the voluntary waiting period (VWP) and possible enrolment in an Ovsynch protocol, 12 or $46 \mathrm{~d}$ later (Neves et al., 2012; Fricke et al., 2014; Dolecheck et al., 2016). When employing AAM, not all cows will be detected in estrus within an economically desirable time, but this interval is not well defined. If a goal is to maximize the use of AAM, it is likely necessary to wait for the length of an estrous cycle so all cows have a chance to be detected in estrus by the system once. The estrous cycle of dairy cows was traditionally reported to be approximately $21 \mathrm{~d}$ in length (Hartigan, 2004), but recent studies suggest the interovulatory interval varies from 18 to $28 \mathrm{~d}$ (mode $=22$ d; Sartori et al., 2004; Remnant et al., 2015). To identify most cyclic cows using an AAM system in the period following the VWP, the system should be used for long enough to include the interovulatory interval of most cows. In previous studies, 22 to $31 \%$ of cows were not detected in estrus in that period (Fricke et al., 2014; Dolecheck et al., 2016), so AAM likely needs to be complemented with use of some TAI. To quantify the performance of AAM systems on commercial dairy farms, it is useful to compare reproductive performance with an AAM system combined with TAI to the exclusive use of the Double Ovsynch protocol, which has a high $\mathrm{P} / \mathrm{AI}$ relative to other TAI protocols (Souza et al., 2008; Herlihy et al., 2012). Although previous studies showed that the use of AAM system in combination with TAI resulted in similar overall performance to the use of TAI alone (Neves et al., 2012; Fricke et al., 2014; Dolecheck et al., 2016), for the present study we hypothesized that the AAM system combined with TAI would have less P/AI than Double Ovsynch. The objective of our study was to compare reproductive performance of cows managed with 1 of 2 reproduction management programs in the early breeding period: exclusive use of Double Ovsynch for first AI, or an AAM system combined with TAI for cows not inseminated based on AAM after 25 d following the VWP.

\section{MATERIALS AND METHODS}

\section{Cows and Housing}

This study was evaluated and approved by the University of Guelph Animal Care Committee (Animal Utilization Protocol \#2676). From April 2014 to June 2015, a randomized controlled trial was conducted in a convenience sample of 2 commercial freestall herds with Holstein cows in Ontario, Canada. The average (and maximal) temperature in spring, summer, fall, and winter were 12.2 (31.2), 16.7 (30.0), 2.8 (22.4), and -9.3 $(9.8)^{\circ} \mathrm{C}$, respectively. During this period, herds 1 and 2 had, on average, 655 and 530 milking cows and an average herd 305-d mature-equivalent milk production from DHIA records of 12,880 and $11,430 \mathrm{~kg}$, respectively. For cows inseminated after an AAM alarm, both herds inseminated cows following an a.m.-p.m. schedule (i.e., the insemination was performed the morning following an afternoon or evening alarm or in the afternoon following a morning or mid-day alarm). According to our hypothesis, we aimed to enroll 1,050 cows to identify a difference in pregnancy at first AI of 32 versus $41 \%$, with $95 \%$ confidence, $80 \%$ power, and a $15 \%$ loss to follow-up, so as to have 448 cows in each treatment for analysis of first service P/AI (Abramson, 2011). Both herds milked 3 times per day. All cows, regardless of their treatment, were equipped with an AAM device within 1 wk postpartum (PP): AfiAct (AfiMilk, Kibbutz Afikim, Israel) in herd 1, and HeatSeeker (BouMatic, Madison, WI) in herd 2. Both systems were in use on the farms for over $1 \mathrm{yr}$ before the study, and system settings that were being used before the study were retained. Both farms were also using TAI protocols to complement AAM before the experiment, but not the Double Ovsynch protocol. To ensure that the TAI protocols were correctly implemented, we provided injection and insemination lists weekly and verbally confirmed that these were followed with the person responsible for reproduction management in each herd.

\section{Treatments}

Cows were assigned to treatments weekly according to their identification number that was assigned sequentially at birth or at first calving in herd 1 and 2 , respectively. The Double Ovsynch treatment consisted of insemination at $85 \pm 3$ DIM using the Double Ovsynch protocol $\left(\mathrm{GnRH}-7 \mathrm{~d}-\mathrm{PGF}_{2 \alpha}-3 \mathrm{~d}-\mathrm{GnRH}\right.$ $-7 \mathrm{~d}-\mathrm{GnRH}-7 \mathrm{~d}-\mathrm{PGF}_{2 \alpha}-56 \mathrm{~h}-\mathrm{GnRH}-12$ to $16 \mathrm{~h}-\mathrm{AI})$. Treatment based on AAM (AAM + Ovsynch) consisted of cows inseminated only based on AAM alarm between 50 and 75 DIM; if no alarm was 

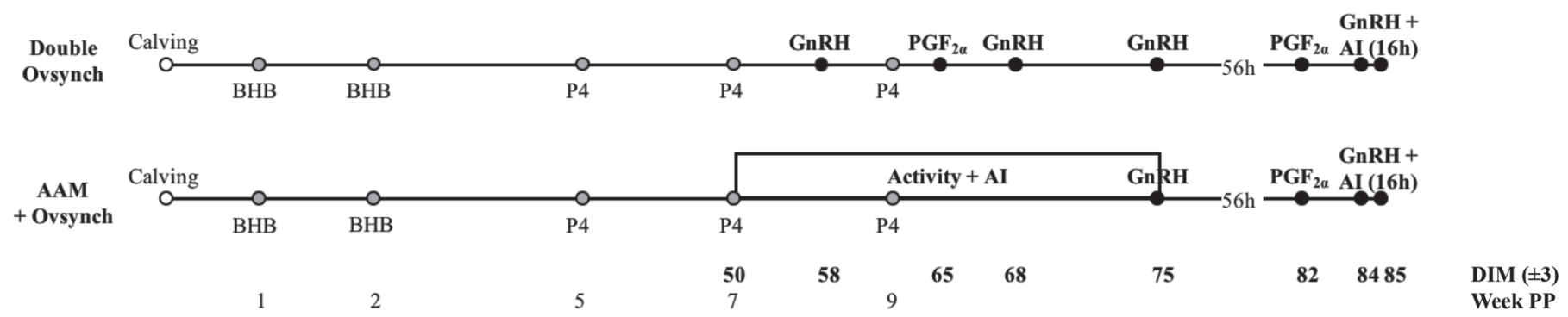

Figure 1. Schematic representation of sampling (gray circles) and treatments (black circles and box). All cows were sampled at wk 1 and 2 postpartum (PP) for BHB, and at wk 5, 7, and $9 \mathrm{PP}$ for progesterone (P4). Cows in the Double Ovsynch treatment started at $58 \pm 3$ DIM so as to be inseminated at $85 \pm 3$ DIM (16 h after the final injection of $\mathrm{GnRH})$. Cows in the automated activity monitoring (AAM) + Ovsynch treatment were inseminated following an alarm on the AAM system between 50 and 75 DIM, or following the Ovsynch program for timed AI at $85 \pm 3$ DIM if not inseminated by 75 DIM.

detected by 75 DIM, cows were enrolled on an Ovsynch protocol for TAI at $85 \pm 3$ DIM (Figure 1). All injections for the TAI programs were administered by herd personnel, following detailed daily lists provided weekly by the investigators. Lists were generated manually for herd 1, and using DairyComp 305 (Valley Agricultural Software, Tulare, CA) for herd 2. Figure 2 presents the flow of cows enrolled in the study, as well as cows that did not receive the preassigned treatment because they were inseminated before the end of the Double Ovsynch protocol $(n=62)$, before the end of the VWP $(n=20)$, or on visual estrus detection without an alarm from the AAM system $(n=48)$. Cows from both treatments were comingled in the same pens and subject to the same diet and management to minimize differences caused by differing management factors. Because of the experimental design, herd and research personnel working with the cows were not blinded to treatments. Pregnancy diagnoses was performed biweekly by the herd veterinarian 28 to $41 \mathrm{~d}$ after insemination using ultrasound.

\section{Blood Sampling and Analyses}

Blood samples were taken from the coccygeal vessels into a sterile tube without anticoagulant (Vacutainer, Becton Dickinson, Franklin Lakes, NJ) at wk 1 (1 to 7 DIM), 2 ( 8 to 14 DIM), 5 (29 to 35 DIM), 7 (43 to 49

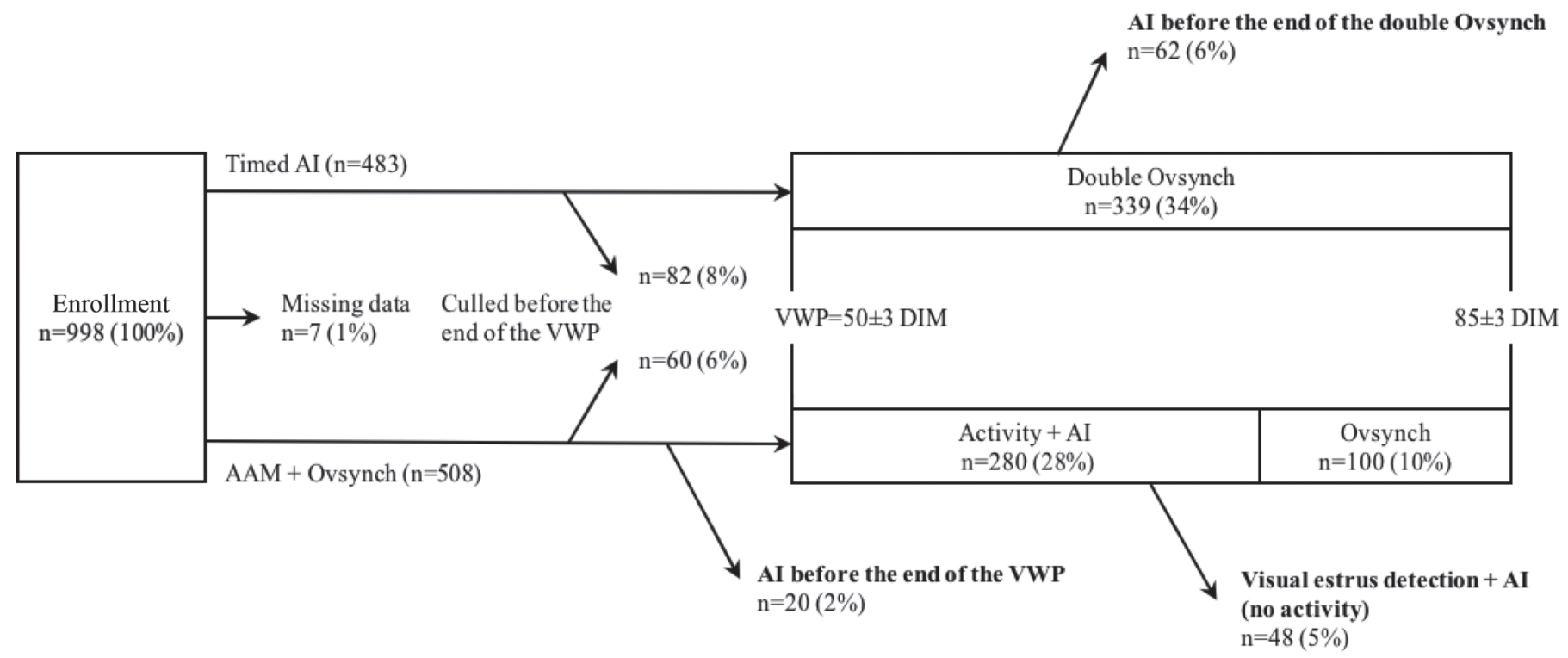

Figure 2. Flow of numbers of lactating dairy cows enrolled in a randomized controlled trial to compare reproductive performance with a program for synchronization for first AI (Double Ovsynch) with estrus detection by automated activity monitoring (AAM) followed by a TAI program (Ovsynch) for cows not detected by 75 DIM. Cows included in the activity + AI, Ovsynch, and Double Ovsynch categories $(\mathrm{n}=719$; $72 \%$ of cows initially enrolled) were used for per-protocol analyses. Additional cows (in bold) were included for intention-to-treat analyses ( $\mathrm{n}=$ $849 ; 85 \%$ of cows initially enrolled). VWP = voluntary waiting period. 
DIM), and 9 (57 to 63 DIM) PP. Blood samples were analyzed immediately when tested for BHB or kept on ice and taken to the laboratory within $6 \mathrm{~h}$. Serum was separated by allowing coagulation of the samples at room temperature for $30 \mathrm{~min}$, and then centrifuged at $1,400 \times g$ at $20^{\circ} \mathrm{C}$ for $15 \mathrm{~min}$. The serum was collected and frozen at $-20^{\circ} \mathrm{C}$ until analyzed, 1 to 8 mo later. Blood samples were analyzed for BHB (wk 1 and 2), and serum samples for progesterone (P4; wk 5, 7, and 9). Hyperketonemia was defined as $\mathrm{BHB} \geq 1.2 \mathrm{mmol} / \mathrm{L}$ (Duffield et al., 2009) and was measured on farm using a validated hand-held meter (Precision Xtra, Abbott, Alameda, CA; Iwersen et al., 2009). Progesterone concentrations were measured using a commercial ELISA kit (Ovucheck Plasma, Biovet, St. Hyacinthe, Quebec, Canada; Broes and LeBlanc, 2014), and cows were classified as being anovulatory (all 3 samples $<1 \mathrm{ng} / \mathrm{mL}$ ) or ovulatory (at least 1 sample $\geq 1 \mathrm{ng} / \mathrm{mL}$ ). The inter- and intra-assay coefficients of variation of this test were 9.8 and $7.2 \%$, respectively. At wk $5 \mathrm{PP}$, vaginal discharge score was obtained using a Metricheck device (Simcro, Hamilton, New Zealand) as described by McDougall et al. (2007; $0=$ no discharge, $1=$ clear mucus, $2=$ mucus with flecks of pus, $3=$ mucopurulent discharge, $4=$ purulent discharge, or $5=$ foul smelling discharge). Purulent vaginal discharge (PVD) was defined as score of 3 or greater. Body condition was scored on a 5-point scale (Ferguson et al., 1994) at wk 7 and categorized as $\leq 2.5,2.75$ to 3.25 , or $\geq 3.5$. Cows culled before the beginning of the VWP or that had missing data were excluded from the study (Figure 2). Individual cow data (parity, and calving, insemination, and culling dates) were extracted from AfiFarm Dairy Farm Management Software (AfiMilk) or DairyComp 305 (Valley Agricultural Software) in herd 1 and 2, respectively. Parity was categorized into primiparous and multiparous, and season at first insemination into winter (January to March), spring (April to June), summer (July to September), or fall (October to December). Monthly weather data from the station closest to the farms was extracted $\left(43^{\circ} 27^{\prime} 39.0^{\prime \prime} \mathrm{N}, 80^{\circ} 22^{\prime} 43.0^{\prime \prime}\right.$; Government of Canada, 2016).

\section{Statistical Analysis}

All statistical analyses were conducted using SAS 9.3 (SAS Institute Inc., Cary, NC). Parity, hyperketonemia, anovulation, BCS class, and PVD were compared between treatments and between herds using chi-squared statistics (FREQ procedure). Time to first insemination was described graphically using the LIFETEST procedure. The probability of pregnancy at first insemination, and by the end of the experimental period (88 DIM), were used as outcomes in logistic regression models (GLIMMIX procedure). Time-to-event analysis for time to pregnancy (to 200 DIM) was done using Cox proportional hazard models (PHREG procedure). In all models, treatment and herd were always included as fixed effects, and parity, season, and anovulation were kept in the model as confounders if the estimate for treatment changed by more than $10 \%$ when the covariate was removed (Maldonado and Greenland, 1993). Interaction terms between treatment and other covariables were kept if their $P$-value was $<0.05$. The fit of the logistic regression models was assessed using the Hosmer and Lemeshow goodness-of-fit test. Outlier (Pearson and deviance residuals), extreme (hat matrix), and influential (DFBeta) covariate patterns were assessed, and models were tested without extreme and influential values when identified (graphically) to ensure robustness of the coefficients (Dohoo et al., 2009). The proportional hazards assumption of the Cox models was tested using Schoenfeld residuals, and by testing an interaction term between treatment and time. The proportional hazards assumption would be violated by the study design, so the model was run only for the period 89 to 200 DIM. Positive and negative correlation scenarios were simulated to ensure that independence of censoring in the Cox proportional hazard models was not an issue (Dohoo et al., 2009). Outliers (deviance residuals) and influential points (score residuals) were also identified, and models were tested without extreme and influential values to ensure robustness of the coefficients (Dohoo et al., 2009). Finally, median time to pregnancy in each treatment was obtained with a nonparametric survival analysis (LIFETEST procedure). Cows that deviated from the protocol (i.e., inseminated before the end of the Double Ovsynch protocol, before the end of the VWP, or on visual estrus detection without an alarm from the AAM system; Figure 2) were kept for the intention-to-treat analysis and excluded in the per-protocol analysis. As recommended by Gupta (2011), results are from the intention-to-treat group are presented, except when otherwise stated.

\section{RESULTS}

A total of 998 Holstein cows were enrolled, 496 from April to October 2014 in herd 1 and 502 from July 2014 to April 2015 in herd 2. Cows were excluded if they were culled before the diagnosis of pregnancy following first AI $(\mathrm{n}=142)$ or because of missing data ( $\mathrm{n}$ $=7)$. The proportion of cows culled was greater $(P<$ $0.01)$ in herd $1(18 \%)$ than in herd $2(10 \%)$. We found no difference in culled cows or missing data between treatments, or in missing data between herds. A total of 401 Double Ovsynch cows and 448 AAM + Ovsynch cows remained in the experiment for analyses, and 
Table 1. Description of cows in a controlled study of reproductive management in early lactation by treatment [Double Ovsynch or automated activity monitoring (AAM) with Ovsynch] and herd

\begin{tabular}{|c|c|c|c|c|c|c|}
\hline \multirow[b]{2}{*}{ Variable $^{1}$} & \multicolumn{3}{|c|}{ Treatment } & \multicolumn{3}{|c|}{ Herd } \\
\hline & $\begin{array}{c}\text { Double Ovsynch, } \\
\mathrm{n}=401(\%)\end{array}$ & $\begin{array}{c}\mathrm{AAM}+\text { Ovsynch } \\
\mathrm{n}=448(\%)\end{array}$ & $P$-value & $\begin{array}{c}1 \\
\mathrm{n}=401(\%)\end{array}$ & $\begin{array}{c}2 \\
\mathrm{n}=448(\%)\end{array}$ & $P$-value \\
\hline Parity & & & 0.29 & & & $<0.01$ \\
\hline Primiparous & 33.2 & 36.6 & & 42.6 & 28.1 & \\
\hline Multiparous & 66.8 & 63.4 & & 57.4 & 71.9 & \\
\hline \multicolumn{7}{|l|}{ Hyperketonemia } \\
\hline \multicolumn{7}{|l|}{ Anovulation } \\
\hline To wk 9 postpartum & 13.1 & 9.7 & 0.11 & 8.6 & 13.7 & 0.02 \\
\hline Based on wk 5 and 7 only & 29.7 & 25.2 & 0.15 & 29.9 & 29.5 & 0.14 \\
\hline BCS & & & 0.39 & & & $<0.01$ \\
\hline$\leq 2.5$ & 14.4 & 11.3 & & 5.0 & 18.9 & \\
\hline$\overline{2} .75$ to 3.25 & 70.0 & 73.3 & & 70.8 & 72.4 & \\
\hline$\geq 3.5$ & 15.6 & 15.4 & & 24.2 & 8.7 & \\
\hline
\end{tabular}

${ }^{1}$ Hyperketonemia was defined as blood BHB $\geq 1.2 \mathrm{mmol} / \mathrm{L}$, anovulation as serum progesterone $<1 \mathrm{ng} / \mathrm{mL}$ at wk 5,7 and 9 , and purulent vaginal discharge (PVD) as mucopurulent or worse vaginal discharge measured with a Metricheck device at wk 5 postpartum.

339 Double Ovsynch cows and 380 AAM + Ovsynch cows remained for the per-protocol analyses (Figure 2). Overall, $35 \%$ of cows were primiparous and $65 \%$ multiparous, which did not differ between treatments but differed $(P<0.01)$ between herds (Table 1$)$. Cows were enrolled during spring (19\%), summer (31\%), fall (29\%), and winter $(21 \%)$. The proportion of cows with hyperketonemia, PVD, high or low BCS, or anovulation did not differ $(P>0.1)$ between treatments, but significantly differed $(P<0.01)$ between herds (Table 1).

Time to first insemination differed $(P<0.01)$ between treatments as expected based on the experimental design, but also between farms $(P<0.01$; Figure 3 ). Overall, $22 \%$ (95\% CI $=19$ to $26 \%$ ) of cows in the AAM + Ovsynch treatment were not detected in estrus between 50 and 75 DIM, but this differed between farms (7\% in herd 1 and $36 \%$ in herd $2 ; P<0.01$ ). Twentyfour percent ( $95 \% \mathrm{CI}=17$ to $33 \%$ ) of the cows in the $\mathrm{AAM}+$ Ovsynch treatment inseminated following the Ovsynch $(\mathrm{n}=100)$ program became pregnant. In the Double Ovsynch treatment, the insemination rates from 50 to 75 DIM were 0.05 (0.03 to 0.09 ) and 0.09 (0.06 to 0.13 ) per 21 cow-days in herd 1 and 2, respectively; between 50 and $88 \mathrm{DIM}$, insemination rates were 0.61 (0.53 to 0.71 ) and 0.65 (0.57 to 0.75$)$ per 21 cow-days in herd 1 and 2, respectively. In the AAM + Ovsynch treatment, the insemination rates $(95 \%$ CI) from 50 to 75 DIM were 1.35 (1.16 to 1.57 ) and 0.59 (0.50 to 0.69) per 21 cow-days in herd 1 and 2, respectively; between 50 and 88 DIM insemination rates were 1.52 (1.32 to $1.76)$ and 0.97 (0.85 to 1.10$)$ per 21 cow-days in herd 1 and 2 , respectively. In herds 1 and 2 respectively, 5 and
$1 \%$ in Double Ovsynch and 6 and $0 \%$ of cows in AAM + Ovsynch were not inseminated by 88 DIM.

Among cows in the Double Ovsynch treatment, P/AI was 33\% among anovular cows and 38\% among cyclic cows $(P=0.44)$. Among cows in the AAM + Ovsynch treatment that were not detected in estrus and received TAI, $15 \%$ were anovular (19\% on farm 1 and $14 \%$ on farm $2 ; P=0.65)$. Nine percent $(\mathrm{n}=29)$ of the cows identified in estrus by the AAM systems were classified as anovular at wk 9 postpartum.

Unadjusted $\mathrm{P} / \mathrm{AI}$ stratified by herd, parity, and treatment are presented in Table 2. Overall, the odds of pregnancy at first AI (Table 3) and by 88 DIM (Table 4) were not different $(P>0.1)$ between treatments, but there were significant $(P \leq 0.05)$ interactions between treatment and herd for both outcomes. Season and anovular status were not associated with these outcomes and we found no interactions of these variables with treatment $(P>0.20)$ in these models. The unadjusted proportions of cows pregnant at first AI, 88 DIM, and 200 DIM were 34,34 , and $69 \%$ in the Double Ovsynch treatment and 29,41 , and $71 \%$ in the AAM + Ovsynch treatment, respectively. The measures of treatment effect differed by 0.6 to $4.6 \%$ between the intentionto-treat and the per-protocol analyses (Table 3 and 4). The interactions showed that cows in the Double Ovsynch treatment had greater odds of being pregnant at first insemination in herd $2(P=0.02$; Figure 4$)$, and the cows in AAM + Ovsynch treatment had greater odds of being pregnant at 88 DIM in herd $1(P<0.01$; Figure 5). Within the AAM + Ovsynch treatment, the probability of pregnancy at first AI varied between cows inseminated following detection of estrus by the 


\section{-.. Double Ovsynch Herd 1 \\ -.. Double Ovsynch Herd 2}

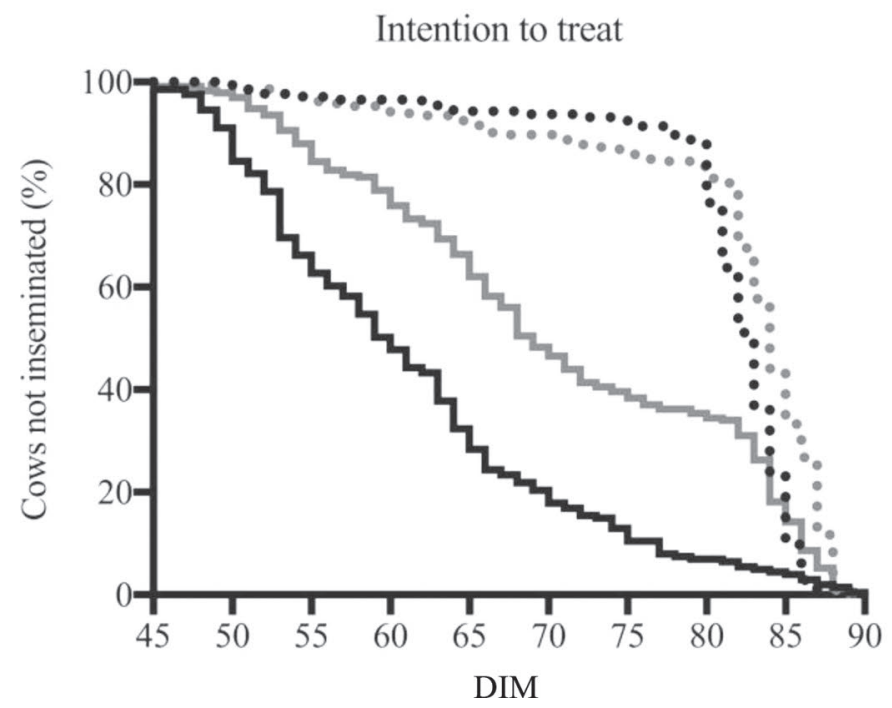
- AAM + Ovsynch Herd 1
- AAM + Ovsynch Herd 2

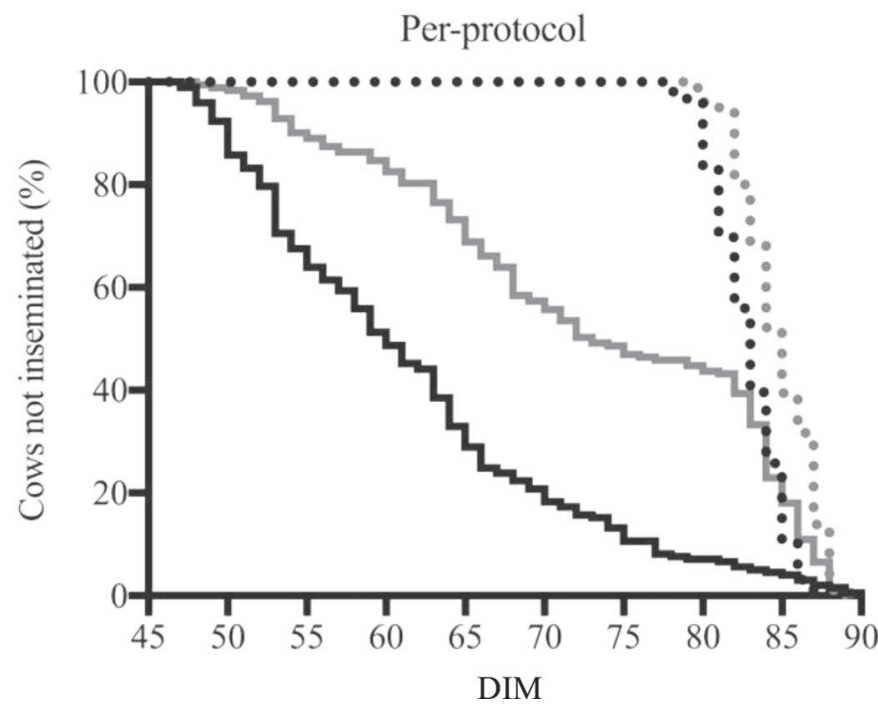

Figure 3. Time to first insemination in 849 cows (intention to treat) and 719 cows (per-protocol) enrolled in a randomized controlled trial evaluating the difference between using a Double Ovsynch protocol and an automated activity monitoring (AAM) system for estrus detection between 50 and 75 DIM (followed by Ovsynch for timed AI in cows not detected in estrus by 75 DIM) in 2 commercial herds.

AAM system $(\mathrm{n}=280 ; 32 \%)$ and cows inseminated following the Ovsynch protocol $(\mathrm{n}=100 ; 24 \%)$, but this was not significantly different (odds ratio $=1.57$, $95 \% \mathrm{CI}=0.76$ to $3.26 ; P=0.23)$. We observed no significant interaction between treatment and parity (at first AI: $P=0.65$; at 88 DIM: $P=0.77$ ), but (Figure 6) multiparous cows were less likely to be pregnant at first AI than primiparous cows in the Double Ovsynch treatment (odds ratio $=0.59,95 \% \mathrm{CI}=0.37$ to 0.94 ; $P=0.03)$.

By design, the daily probability of pregnancy differed $(P<0.01)$ between treatments from 50 to 88 DIM. Between 89 and 200 DIM, the proportionality of hazards was respected and we noted no difference in time to pregnancy between treatments $(P=0.19)$, but did find an interaction between treatment and herd. In herd 1, cows in the Double Ovsynch treatment became pregnant at a lesser rate than cows in AAM + Ovsynch treatment, whereas in herd 2 cows in the Double Ovsynch treatment became pregnant at a greater rate than cows in AAM + Ovsynch treatment (herd 1: HR $=0.80,95 \% \mathrm{CI}=0.57$ to $1.12 ;$ herd $2: \mathrm{HR}=1.33,95 \%$ $\mathrm{CI}=0.96$ to $1.85 ; P=0.03)$. The median $(95 \% \mathrm{CI})$ time to pregnancy was 118 (110 to 129) and 110 (101 to 117) DIM for Double Ovsynch and AAM + Ovsynch, respectively (Figure 7 ). In herd 1 , the median time to pregnancy was 110 (106 to 129) and 98 (88 to 113) DIM for the Double Ovsynch and AAM + Ovsynch,

Table 2. Unadjusted pregnancy per AI (P/AI) at first insemination stratified by herd, parity, and treatment [Double Ovsynch or automated activity monitoring (AAM) with Ovsynch]

\begin{tabular}{lllrrc}
\hline Herd & Parity & Treatment & $\mathrm{n}$ & $\mathrm{P} / \mathrm{AI}(\%)$ & $95 \%$ CI \\
\hline 1 & Primiparous & Double Ovsynch & 78 & 35.5 & $26.7-46.8$ \\
& \multirow{2}{*}{ Multiparous } & AAM & 93 & 35.2 & $26.1-45.4$ \\
& & Double Ovsynch & 107 & 27.6 & $19.6-37.2$ \\
2 & AAM & 123 & 31.8 & $23.8-41.0$ \\
& Primiparous & Double Ovsynch & 55 & 45.5 & $33.0-58.5$ \\
& & AAM & 71 & 32.4 & $22.6-44.0$ \\
& Multiparous & Double Ovsynch & 161 & 32.9 & $26.1-40.6$ \\
& AAM & 161 & 23.0 & $17.1-30.1$ \\
\hline
\end{tabular}


Table 3. Logistic regression models for pregnancy at first insemination in 849 cows (intention to treat) and 719 cows (per-protocol) enrolled in a randomized controlled trial evaluating the difference between using a Double Ovsynch protocol with AI at $85 \pm 3$ DIM, and an automated activity monitoring (AAM) system combined with Ovsynch when required for first insemination ${ }^{1}$

\begin{tabular}{|c|c|c|c|c|c|c|c|c|c|c|}
\hline Item & $\mathrm{n}$ & $\begin{array}{c}\text { Cows } \\
\text { pregnant } \\
(\%)\end{array}$ & \multicolumn{3}{|c|}{ Intention-to-treat } & $\mathrm{n}$ & $\begin{array}{c}\text { Cows } \\
\text { pregnant } \\
(\%)\end{array}$ & \multicolumn{3}{|c|}{ Per-protocol } \\
\hline Double Ovsynch & 401 & 34.7 & Referent & & & 339 & 36.3 & Referent & & \\
\hline AAM & 448 & 30.3 & 0.82 & $0.61-1.10$ & 0.18 & 380 & 30.7 & 0.78 & $0.57-1.07$ & 0.12 \\
\hline \multicolumn{11}{|l|}{ Herd } \\
\hline \multicolumn{11}{|l|}{ Parity } \\
\hline Primiparous & 297 & 36.7 & Referent & & & 261 & 38.5 & Referent & & \\
\hline Multiparous & 552 & 28.5 & 0.69 & $0.50-0.94$ & 0.02 & 458 & 28.7 & 0.65 & $0.46-0.90$ & 0.01 \\
\hline Treatment by herd interaction & & & & & 0.05 & & & & & 0.07 \\
\hline
\end{tabular}

${ }^{1}$ The effect of treatment depended on herd and the treatment by herd interaction is described in Figure 4 .

${ }^{2}$ Estimated population marginal proportion (LSM) of cows pregnant at first insemination in each category of predictor.

respectively. In herd 2, it was 126 (113 to 139) and 116 (105 to 131) DIM for the Double Ovsynch and AAM + Ovsynch, respectively.

\section{DISCUSSION}

Our study compared reproductive performance between 2 approaches to management of first insemination on dairy cattle commercial farms, one based on the use of AAM combined with TAI if cows were not identified in estrus by $25 \mathrm{~d}$ after the VWP, and the other based exclusively on TAI. Heavy reliance on AAM was compared with a Double Ovsynch protocol, which has been reported to result in high $\mathrm{P} / \mathrm{AI}$, particularly in primiparous cows, in intensively managed confined dairy herds (Souza et al., 2008; Herlihy et al., 2012). The study design provided for all cows in each treatment to be inseminated by 88 DIM. The design also allowed a proportion of cows in the AAM + Ovsynch treatment to be inseminated twice by the time cows in the Double Ovsynch treatment received their first insemination, which explains the difference between the proportions of cows pregnant in the AAM + Ovsynch treatment at first AI and at 88 DIM. The proportion of cows pregnant at 88 DIM is not a biological or specific economic endpoint but, given our design, was used to describe reproductive performance with the 2 reproductive management practices. One of the potential advantages of using an AAM system is to have the opportunity to reinseminate cows at approximately 3 -wk intervals. Overall, the treatments offered similar performance, as shown in previous studies (Neves et al., 2012; Fricke et al., 2014); yet, as in other trials with multiple herds, relative performance of AAM compared with TAI differed between herds (Neves et al., 2012; Dolecheck et al., 2016; Burnett et al., 2017).

Table 4. Logistic regression models for pregnancy by 88 DIM (the end of the experimental period) in 849 cows (intention to treat) and 719 cows (per-protocol) enrolled in a controlled trial evaluating the difference between using a Double Ovsynch protocol with AI at $85 \pm 3$ DIM, and an automated activity monitoring (AAM) system combined with Ovsynch when required for first insemination ${ }^{1}$

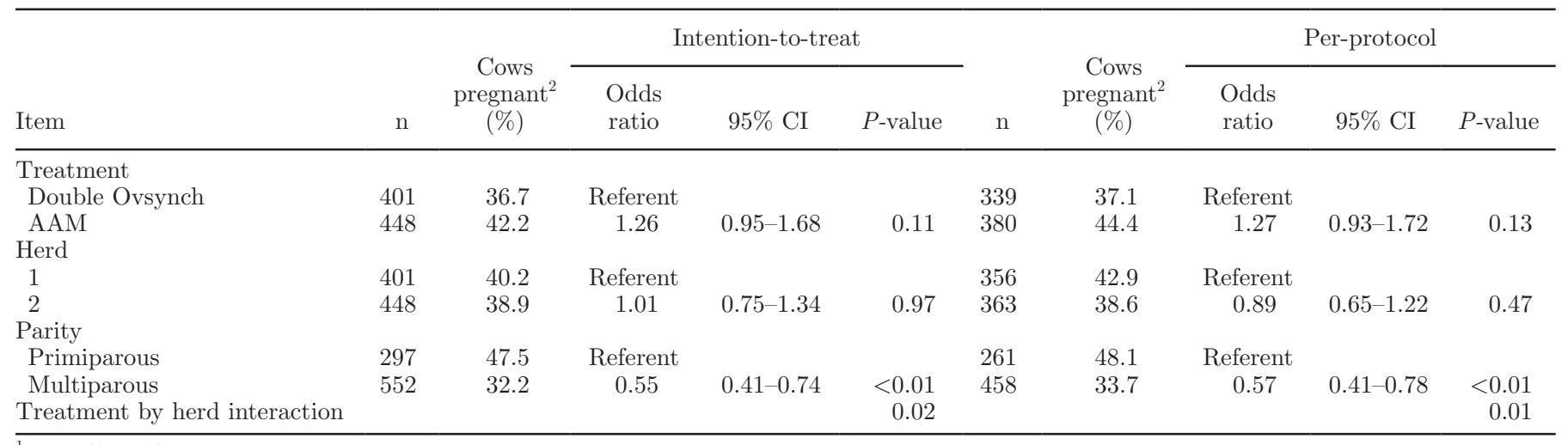

${ }^{1}$ The effect of treatment depended on herd and the treatment by herd interaction is detailed in Figure 5.

${ }^{2}$ Estimated population marginal proportion (LSM) of cows pregnant at first insemination in each category of predictor. 


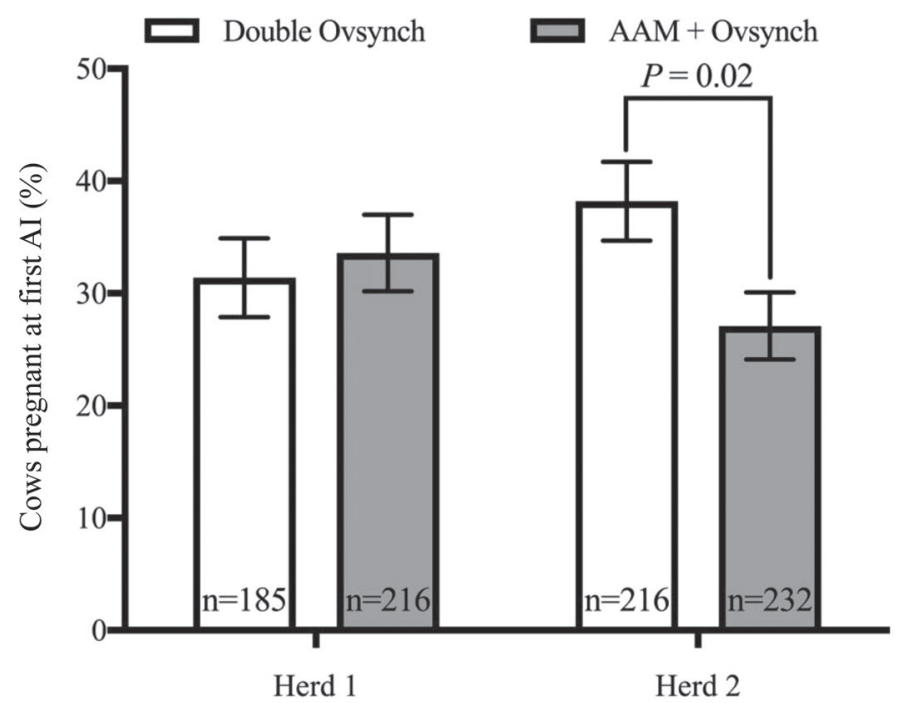

Figure 4. Effect of treatment on the proportion of pregnancy at first AI in 849 cows (intention-to-treat analysis), stratified by herd. The marginal means $( \pm \mathrm{SD})$ were obtained from a logistic regression model including treatment $(P=0.18)$, herd $(P=0.98)$, parity $(P=$ $0.02)$, and treatment by herd interaction $(P=0.05)$. The treatments were Double Ovsynch protocol and automated activity monitoring (AAM) system combined with Ovsynch when required for first insemination. We found no difference between AAM and Double Ovsynch in herd $1(P=0.65)$, but noted a difference in herd $2(P=0.02)$. We also found no difference between herd 1 and herd 2 for $\operatorname{AAM}(P=0.15)$ or for Double Ovsynch $(P=0.17)$.

One important result from the present study is that the effect of the treatments differed between the 2 herds. Cows in the Double Ovsynch treatment in one herd were more likely to become pregnant at first AI than cows in the AAM + Ovsynch treatment. On the contrary, in the other herd, cows in the AAM + Ovsynch treatment were more likely to be pregnant by 88 DIM than cows in the Double Ovsynch treatment. The interaction of treatment with herd remained for the time to pregnancy up to 200 DIM. These interactions point to differences among herds in the relative performance of TAI and AAM. This variability among herds has been shown previously for AAM (Neves et al., 2012; Dolecheck et al., 2016), but has not been reported for Double Ovsynch (i.e., no farm by treatment interactions; Souza et al., 2008; Herlihy et al., 2012). The present study was not designed to explain the variability in response to treatment between herds, but it can be hypothesized that differences in farm-specific characteristics and management, as well as the use of different AAM systems, might have played a role. In particular, as may be expected, AAM performed better in the herd in which the insemination rate was greater. We acknowledge that, in the present study, the AAM system was confounded with herd. Although no clear peer-reviewed data exist documenting differences in performance among AAM hardware and software systems as used commercially, this is one possible source of between-herd differences in responses to treatment.

Although we cannot formally explain the reasons behind the differences between herds, we noted that the success of estrus detection (i.e., greater insemination rate in herd 1; Figure 3) was likely an important determinant of the results that we obtained. In the $\mathrm{AAM}+$ Ovsynch treatment, the insemination rate was $57 \%$ greater in herd 1 than in herd 2 from 50 to 88 DIM (1.52 vs. 0.97 inseminations per 21 cow-days). The probability of pregnancy at first AI and by 88 DIM was also greater in herd 1 than in herd 2 for AAM + Ovsynch treatment. This difference is also reflected in the proportion of cows not identified in estrus by the AAM before 75 DIM. The proportion of cows $(7 \%$ in herd 1 and $36 \%$ in herd 2) not detected in estrus between 50 and 75 DIM is in the expected range, but this represents the ends of the distribution (Fricke et al., 2014; Dolecheck et al., 2016). Our results with AAM + Ovsynch are consistent with controlled trials (Tenhagen et al., 2004) and observational studies (Ferguson and Skidmore, 2013; Denis-Robichaud et al., 2016) that show that a greater insemination rate is a

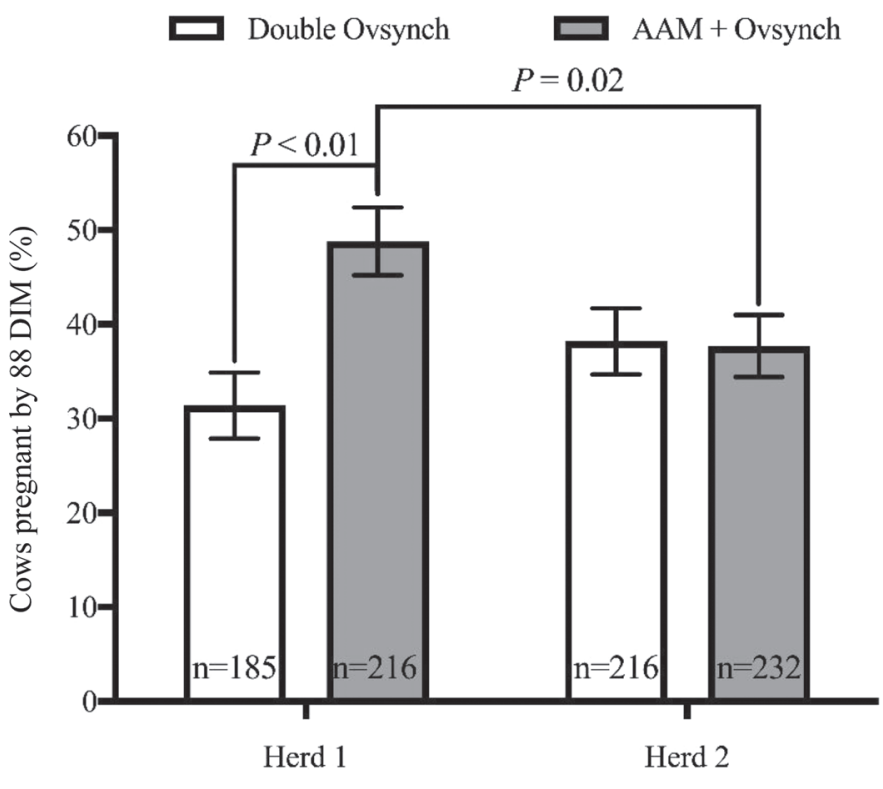

Figure 5. Effect of treatment on the proportion of pregnancy by 88 DIM in 849 cows (intention-to-treat analysis), stratified by herd. The marginal means $( \pm \mathrm{SD})$ were obtained from a logistic regression model including treatment $(P=0.11)$, herd $(P=0.97)$, parity $(P<0.01)$, and treatment by herd interaction $(P=0.02)$. The treatments were Double Ovsynch protocol and automated activity monitoring (AAM) system combined with Ovsynch when required for first insemination. We found no difference between AAM and Double Ovsynch in herd 2 $(P=0.61)$, but noted a difference in herd $1(P<0.01)$. We also found no difference between herd 1 and herd 2 for Double Ovsynch $(P=$ $0.12)$, but noted a difference for $\operatorname{AAM}(P=0.02)$. 
key determinant of good performance when employing estrus detection as part of a reproductive management program. Barring a substantial reduction in $\mathrm{P} / \mathrm{AI}$, more inseminations will result in more pregnancies per unit of time, in this case contributing to the difference between treatments in the proportion of cows pregnant by 88 DIM in herd 1 (Figure 5). Factors such as the prevalence of lameness, stocking density in the breeding pens, and the sensitivity of the AAM system are likely involved in the probability of identifying cows in estrus by an AAM system, but were not assessed in the present study.

The data in Table 3 show that herd 1 had $43 \%$ primiparous cows, which (other things being equal) would be expected to favor the performance of Double Ovsynch, yet this herd had only $31 \%$ P/AI with Double Ovsynch. In contrast, primiparous cows in herd 2 had approximately the expected success with Double Ovsynch (45\% P/AI; Table 2). Herd 1 also had a fairly low prevalence of ketosis, low prevalence of anovulation to wk 9 postpartum (9\%), and only $5 \%$ of cows with BCS $\leq 2.5$ at wk 7 . All these indicators of metabolic

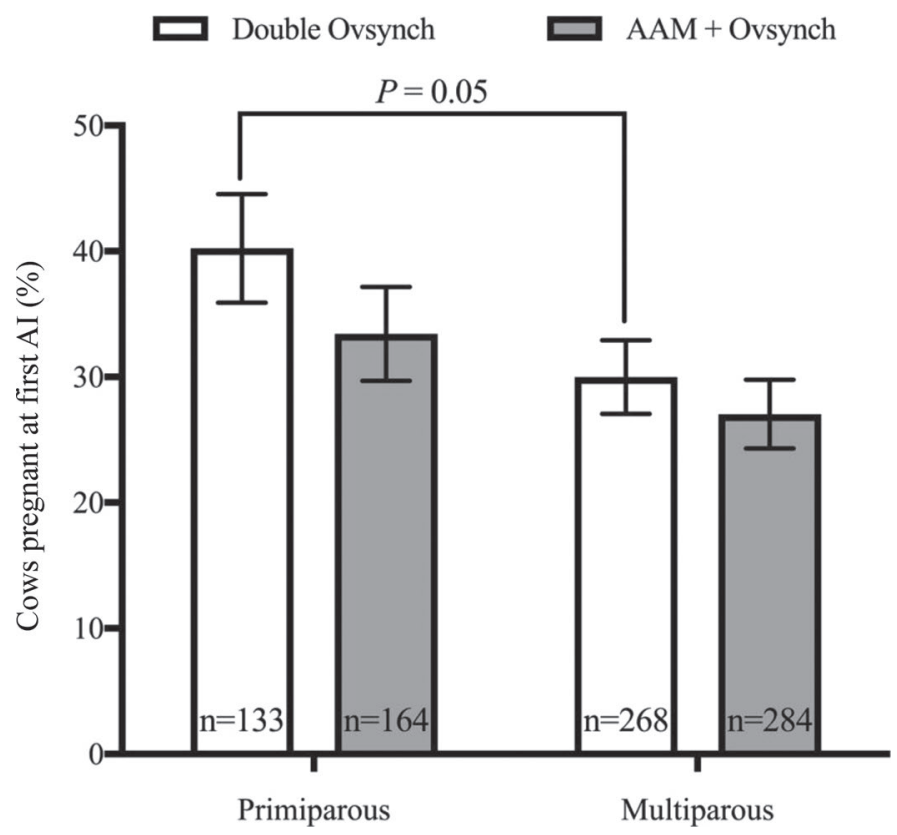

Figure 6. Effect of treatment on the proportion of pregnancy at first AI in 849 cows (intention-to-treat analysis), stratified by parity. The marginal means $( \pm \mathrm{SD})$ were obtained from a logistic regression model including treatment $(P=0.16)$, herd $(P=0.99)$, parity $(P=$ $0.02)$, treatment by herd interaction $(P=0.04)$, and treatment by parity interaction $(P=0.64)$. The treatments were Double Ovsynch protocol and automated activity monitoring (AAM) system combined with Ovsynch when required for first insemination. We observed no difference between AAM and Double Ovsynch for primiparous $(P=$ $0.23)$ or multiparous cows $(P=0.46)$. We also found no difference between primiparous and multiparous cows for AAM $(P=0.16)$, but noted a difference for Double Ovsynch $(P=0.05)$. health were more favorable in herd 1 than in herd 2 , but pregnancy to first AI was not greater in herd 1. The insemination rate in the AAM + Ovsynch treatment was, on the other hand, greater in herd 1, which is likely to be influenced by cyclicity and metabolic health. Despite the lower than expected P/AI at first service, these factors may have contributed to herd 1 having $44 \%$ of cows pregnant by the end of the experimental period at 88 DIM, driven by cows receiving a second AI during the experimental period.

Not detecting cows in estrus by the AAM system is one of the limitations of managing reproduction with these systems. Published field trials on reproductive performance with AAM systems have employed a different system (Heatime, SCR Engineers Ltd., Netanya, Israel; Aungier et al., 2012; Neves et al., 2012; Valenza et al., 2012) than those used in the present study. The percentage of alarms occurring in a true estrus period (i.e., the positive predictive value), defined as low progesterone or agreement with ovarian structures assessed by ultrasound, were $74 \%$ (Holman et al., 2011) for AfiTag (Afimilk) and 86\% (Madureira et al., 2015) for HeatSeeker-TX (BouMatic). This variability between the accuracy of the systems suggests a difference between systems, but does not indicate how this could have affected our results. Future studies should address the performance and comparability of different AAM systems as well as the use of different estrus signal thresholds and data-processing algorithms within the same system.

Prolonged postpartum anovulation can have an important effect on the performance of both AAM and TAI (Gümen et al., 2003; Walsh et al., 2007). The proportion of cows pregnant at first insemination in the AAM + Ovsynch treatment (approximately 30\%) was similar to recent studies (Neves et al., 2012; Fricke et al., 2014). The cows in the AAM + Ovsynch treatment inseminated following an Ovsynch protocol had low P/ AI (24\%), but these were a subgroup that had not been detected in estrus by AAM, of which $15 \%$ were anovular and, consequently, less likely to be pregnant following a single Ovsynch protocol (Gümen et al., 2003; Bisinotto et al., 2010).

As shown in Table 2, the Double Ovsynch treatment in both herds had lower P/AI for both primiparous and multiparous cows than reported in some studies (Souza et al., 2008; Herlihy et al., 2012), but comparable overall to other studies in commercial herds (Astiz and Fargas, 2013; Dirandeh et al., 2015). The use of a second $\mathrm{PGF}_{2 \alpha} 24 \mathrm{~h}$ after the first in the final Ovsynch program has been shown to decrease progesterone concentration for the last $\mathrm{GnRH}$ and increase fertility in multiparous cows (Brusveen et al., 2009; Wiltbank et al., 2015). In the present study, P/AI for multiparous 


\section{... Double Ovsynch — AAM + Ovsynch}

Intention to treat

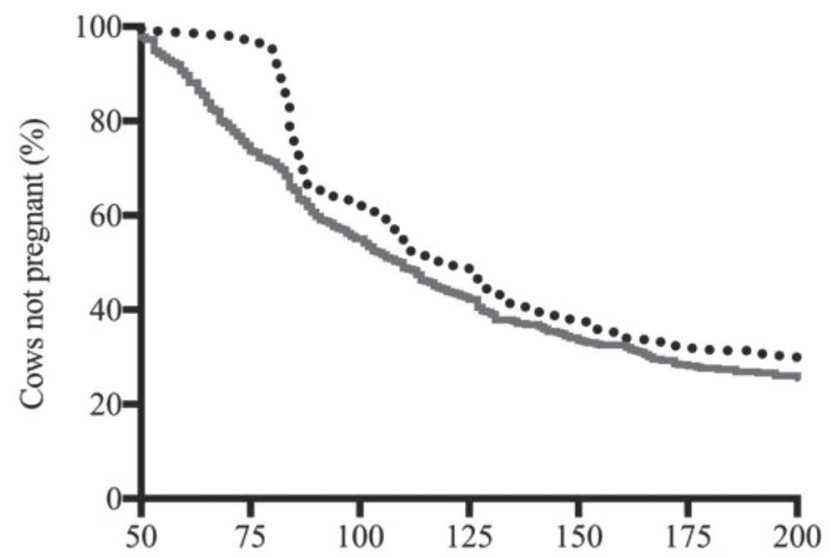

Intention to treat - herd 1

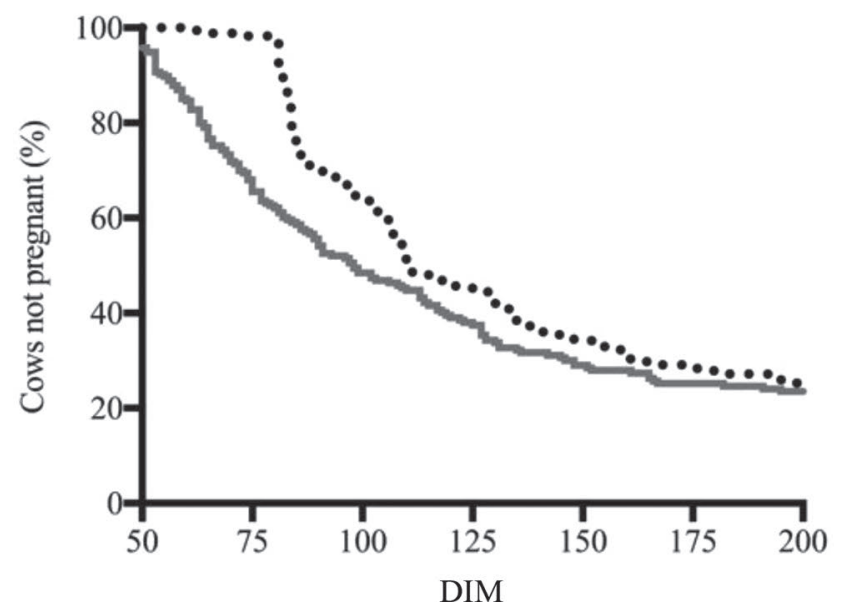

Per-protocol

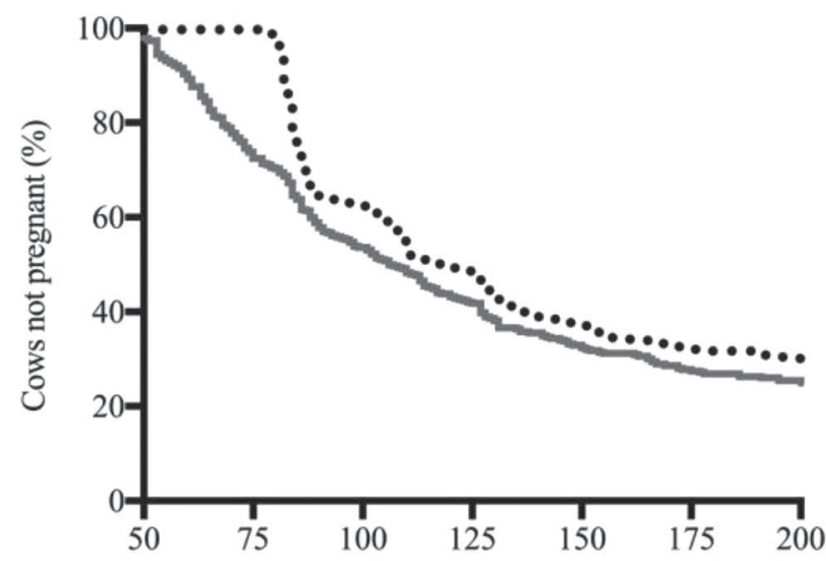

Intention to treat - herd 2

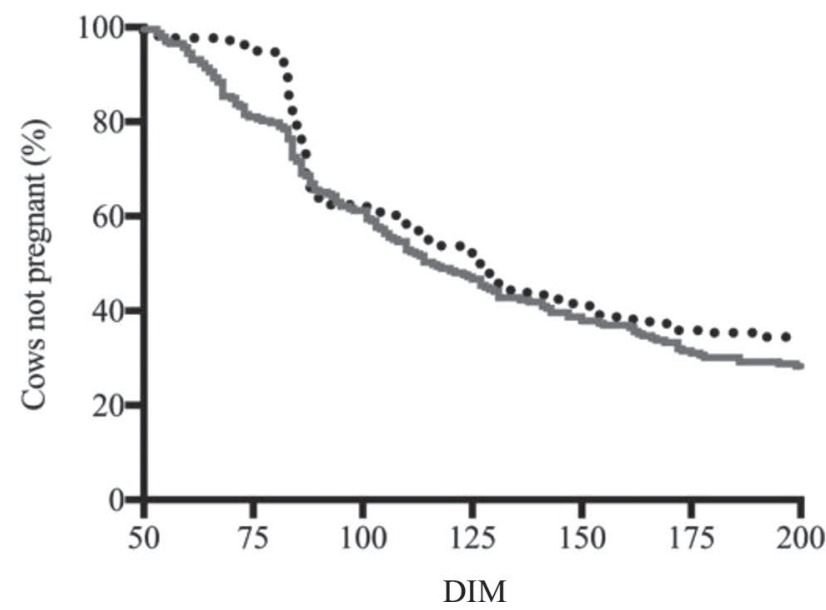

Figure 7. Time to pregnancy in 849 cows (intention to treat), stratified by herd (herd 1: $\mathrm{n}=496$; herd $2: \mathrm{n}=502$ ), and 719 cows (perprotocol) enrolled in a randomized controlled trial evaluating the difference between using a Double Ovsynch protocol and an automated activity monitoring (AAM) system for estrus detection between 50 and 75 DIM, followed by Ovsynch for timed AI in cows not detected in estrus by 75 DIM. In herd 1, the median time to pregnancy was 98 (88 to 113) DIM and 110 (106 to 129) DIM for the AAM and the Double Ovsynch treatment, respectively. In herd 2, it was 116 (105 to 131) DIM and 126 (113 to 139) DIM for the AAM and the Double Ovsynch treatment, respectively.

cows following the Double Ovsynch program was less than for primiparous cows. It is likely that a second $\mathrm{PGF}_{2 \alpha}$ would have increased the performance of the program (Wiltbank et al., 2015).

Compliance (administration of the correct dose and product at the correct time) is critical for synchronization programs to achieve their potential performance (Risco and Melendez, 2011), and this has been identified to be a challenge by dairy farmers in a large Canadian survey (Denis-Robichaud, 2016). A possible explanation for the less-than-expected performance of the Double Ovsynch in the present study is less-than- perfect compliance to the injection schedule. In commercial herds, even during controlled trials, compliance with synchronization protocols has been reported to be 67 to $81 \%$ (Jordan et al., 2002; Stevenson and Phatak, 2005). In models of performance, compliance of 85 to $95 \%$ with TAI protocols had substantial effects on relative performance and economic merit of these programs (Galvão et al., 2013). In the present study, daily paper schedules were printed for the managers of the herds to minimize this type of issue, but we did not have data to evaluate the injection-level compliance with the programs. We noted that in herds 1 and 2, respectively, 
6 and $0 \%$ of cows in AAM + Ovsynch and 5 and $1 \%$ of cows in Double Ovsynch did not receive AI by 88 DIM, an indicator of compliance with the study protocol. This does not rule out failure to administer 1 or more preceding injections correctly, but indicates that the herd managers did not knowingly fail or abort the TAI protocol in most cases. Neves et al. (2012) showed that, depending on the herd, compliance with an AAM system was also an issue. In their research, 2 of the 3 herds had lower P/AI for cows inseminated following visual detection of estrus compared with cows inseminated following an AAM alarm. In the present study, $6 \%$ of the cows assigned to Double Ovsynch were inseminated before the end of the protocol and $5 \%$ of the cows in the AAM + Ovsynch treatment were inseminated without an alarm (Figure 2). This suggests that managers chose to inseminate cows that they observed in estrus, prioritizing this observation over prescribed protocols.

Due to the high performance of the Double Ovsynch in previous reports (Souza et al., 2008; Herlihy et al., 2012), the sample size for our study was calculated to identify a difference of probability of pregnancy at first insemination between the Double Ovsynch and the AAM + Ovsynch treatment. We enrolled 998 cows of our planned 1,050, based on detecting a difference in first service $\mathrm{P} / \mathrm{AI} \geq 9 \%$ points (specifically, 32 vs. $41 \%$ ). Our agreements with the participating herds determined the end dates of enrolment. We had greaterthan-expected attrition of cows for the final analyses, particularly for the per-protocol analyses. We did have the planned number of cows in the intention-to-treat analysis in the AAM + Ovsynch treatment, but 47 cows $(10 \%)$ fewer than planned in the Double Ovsynch treatment. A study powered to detect the magnitude of difference in $\mathrm{P} / \mathrm{AI}$ that we observed overall (approximately 32 vs. $36 \%$ ) would require 2,200 cows per treatment in the final analysis, assuming no interactions with treatment. The present results, similar to previous trials (Neves et al., 2012; Fricke et al., 2014; Dolecheck et al., 2016), suggest overall noninferiority of performance of AAM and TAI, but with apparently important between-herd variability. The difference of relative performance among herds has been repeated across studies (Neves et al., 2012; Dolecheck et al., 2016); exploration of the variables determining differences among herds would require different designs and much larger numbers of herds and cows. The demands of implementing 2 reproductive management programs in parallel in commercial herds remains a barrier to such a study.

The intention-to-treat analyses were presented as the main approach, as they give a more conservative estimate and are recommended by the scientific com- munity (Gupta, 2011). The estimates obtained by the per-protocol analyses were, however, very similar, which indicates that including the cows that deviated from the protocol did not overly influence the results in our study.

The fact that $9 \%$ of the cows identified in estrus by the AAM system were classified as anovulatory at wk 9 postpartum suggests that some false-positive estrus alerts occurred. Other studies of AAM systems found positive predictive values for estrus alerts between 74 and 94\%, depending on the system (Holman et al., 2011; Valenza et al., 2012; Madureira et al., 2015), which implies some false-positive alarms. On the other hand, it is likely that some cows classified as anovulatory at wk 9 postpartum started cycling and expressed estrus before 75 DIM (Sartori et al., 2004; Remnant et al., 2015). We acknowledge that in the Double Ovsynch treatment cows received an injection of $\mathrm{GnRH} 4$ to $5 \mathrm{~d}$ before the wk 9 sample was taken to measure $\mathrm{P} 4$, which may have induced ovulation in anovular cows, and thus reduced the apparent prevalence of anovulation in this treatment. However, our experimental design was intended to reflect realistic application of the Double Ovsynch program and, to the extent that it may induce first ovulation, this contributes to the external validity of the results because this would be the case in the field.

\section{CONCLUSIONS}

The present study did not detect overall differences in the probability of pregnancy at first AI or by 88 DIM, or in time to pregnancy, when comparing exclusive use of Double Ovsynch to a combination of estrus detection by AAM for $25 \mathrm{~d}$ and Ovsynch under commercial farm conditions; however, we noted interactions between treatment and herd that indicated variability in the relative performance of these management tools among herds. The different AAM systems and proportions of primiparous, thin, anovular, and hyperketonemic cows between herds as well as unmeasured herd variables (such as, but not limited to, the prevalence of lameness, incidence of postpartum disease, and the degree of compliance with TAI protocols) likely contributed to the differences in relative performance. We can infer that insemination rate is important to successful use of a reproductive management program that employs estrus detection. The findings of the present study point to the existence of herd-specific variables that influence and interact with the performance of reproductive management tools. Future studies should evaluate these determinants of performance in greater detail, with comprehensive data collection and with large numbers of cows and herds. 


\section{ACKNOWLEDGMENTS}

This project was funded by the Dairy Research Cluster Initiative [Dairy Farmers of Canada (Ottawa, Canada), Agriculture and Agri-Food Canada (Ottawa, Canada), the Canadian Dairy Network (Guelph, Canada), and the Canadian Dairy Commission (Ottawa, Canada)]. We thank the owners and employees of the participating farms for their willingness to participate. We also acknowledge the students who woke up in the middle of the night to make this project possible.

\section{REFERENCES}

Abramson, J. H. 2011. WINPEPI updated: Computer programs for epidemiologists, and their teaching potential. Epidemiol. Perspect. Innov. 8:1. https://doi.org/10.1186/1742-5573-8-1.

Astiz, S., and O. Fargas. 2013. Pregnancy per AI differences between primiparous and multiparous high-yield dairy cows after using Double Ovsynch or G6G synchronization protocols. Theriogenology 79:1065-1070. https://doi.org/10.1016/j.theriogenology.2013 .01 .026 .

At-Taras, E. E., and S. L. Spahr. 2001. Detection and characterization of estrus in dairy cattle with an electronic heatmount detector and an electronic activity tag. J. Dairy Sci. 84:792-798. https://doi .org/10.3168/jds.S0022-0302(01)74535-3.

Aungier, S. P., J. F. Roche, M. Sheehy, and M. A. Crowe. 2012. Effects of management and health on the use of activity monitoring for estrus detection in dairy cows. J. Dairy Sci. 95:2452-2466. https:// doi.org/10.3168/jds.2011-4653.

Bisinotto, R. S., R. C. Chebel, and J. E. Santos. 2010. Follicular wave of the ovulatory follicle and not cycling status influences fertility of dairy cows. J. Dairy Sci. 93:3578-3587. https://doi.org/10.3168/ jds.2010-3047.

Broes, A., and S. J. LeBlanc. 2014. Comparison of commercial progesterone assays for evaluation of luteal status in dairy cows. Can. Vet. J. 55:582-584.

Brusveen, D. J., A. H. Souza, and M. C. Wiltbank. 2009. Effects of additional prostaglandin F2alpha and estradiol-17beta during Ovsynch in lactating dairy cows. J. Dairy Sci. 92:1412-1422. https://doi.org/10.3168/jds.2008-1289.

Burnett, T. A., A. M. L. Madureira, B. F. Silper, A. C. C. Fernandes, and R. L. A. Cerri. 2017. Integrating an automated activity monitor into an artificial insemination program and the associated risk factors affecting reproductive performance of dairy cows. J. Dairy Sci. https://doi.org/10.3168/jds.2016-12246. 100:5005-5018.

Caraviello, D. Z., K. A. Weigel, P. M. Fricke, M. C. Wiltbank, M. J. Florent, N. B. Cook, K. V. Nordlund, N. R. Zwald, and C. L. Rawson. 2006. Survey of management practices on reproductive performance of dairy cattle on large US commercial farms. J. Dairy Sci. 89:4723-4735. https://doi.org/10.3168/jds.S0022 $-0302(06) 72522-\mathrm{X}$.

Denis-Robichaud, J. 2016. Assessment of automated activity monitors for managing reproduction in dairy cows. $\mathrm{PhD}$ thesis. Univ. Guelph, Guelph, Canada.

Denis-Robichaud, J., R. L. A. Cerri, A. Jones-Bitton, and S. J. LeBlanc. 2016. Survey of reproduction management on Canadian dairy farms. J. Dairy Sci. 99:9339-9351. https://doi.org/10.3168/jds .2016-11445.

Dirandeh, E., A. R. Roodbari, and M. G. Colazo. 2015. DoubleOvsynch, compared with presynch with or without GnRH, improves fertility in heat-stressed lactating dairy cows. Theriogenology 83:438-443. https://doi.org/10.1016/j.theriogenology.2014.10 .011 .

Dohoo, I. R., S. W. Martin, and H. Stryhn. 2009. Veterinary Epidemiologic Research. 2nd ed. VER Inc., Charlottetown, PE, Canada.
Dolecheck, K. A., W. J. Silvia, G. Heersche, C. L. Wood, K. J. McQuerry, and J. M. Bewley. 2016. A comparison of timed artificial insemination and automated activity monitoring with hormone intervention in 3 commercial dairy herds. J. Dairy Sci. 99:1506-1514. https://doi.org/10.3168/jds.2015-9914.

Dubuc, J., and J. Denis-Robichaud. 2017. A dairy herd-level study of postpartum diseases and their association with reproductive performance and culling. J. Dairy Sci. 100:3068-3078. https://doi .org/10.3168/jds.2016-12144.

Duffield, T. F., K. D. Lissemore, B. W. McBride, and K. E. Leslie. 2009. Impact of hyperketonemia in early lactation dairy cows on health and production. J. Dairy Sci. 92:571-580. https://doi.org/ 10.3168/jds.2008-1507.

Ferguson, J. D., D. T. Galligan, and N. Thomsen. 1994. Principal descriptors of body condition score in Holstein cows. J. Dairy Sci. 77:2695-2703. https://doi.org/10.3168/jds.S0022-0302(94)77212 $-\mathrm{X}$.

Ferguson, J. D., and A. Skidmore. 2013. Reproductive performance in a select sample of dairy herds. J. Dairy Sci. 96:1269-1289. https:// doi.org/10.3168/jds.2012-5805.

Firk, R., E. Stamer, W. Junge, and J. Krieter. 2002. Automation of oestrus detection in dairy cows: a review. Livest. Prod. Sci. 75:219232. https://doi.org/10.1016/S0301-6226(01)00323-2.

Fricke, P. M., J. O. Giordano, A. Valenza, G. Lopes, M. C. Amundson, and P. D. Carvalho. 2014. Reproductive performance of lactating dairy cows managed for first service using timed artificial insemination with or without detection of estrus using an activitymonitoring system. J. Dairy Sci. 97:2771-2781. https://doi.org/10 .3168/jds.2013-7366.

Galvão, K. N., P. Federico, A. De Vries, and G. M. Schuenemann. 2013. Economic comparison of reproductive programs for dairy herds using estrus detection, timed artificial insemination, or a combination. J. Dairy Sci. 96:2681-2693. https://doi.org/10.3168/ jds.2012-5982.

Government of Canada. 2016. Climate Archive. Accessed Aug. 28, 2016. http://climate.weather.gc.ca/.

Gümen, A., J. N. Guenther, and W. C. Wiltbank. 2003. Follicular size and response to Ovsynch versus detection of estrus in anovular and ovular lactating dairy cows. J. Dairy Sci. 86:3184-3194. https://doi.org/10.3168/jds.S0022-0302(03)73921-6.

Gupta, S. K. 2011. Intention-to-treat concept: A review. Perspect. Clin. Res. 2:109-112. https://doi.org/10.4103/2229-3485.83221.

Hartigan, P. J. 2004. Reproductive physiology in cattle. Pages 471-505 in Bovine Medicine: Diseases and Husbandry of Cattle. 2nd ed. O. Blackwell Science Ltd., Oxford, UK.

Herlihy, M. M., J. O. Giordano, A. H. Souza, H. Ayres, R. M. Ferreira, A. Keskin, A. B. Nascimento, J. N. Guenther, J. M. Gaska, S. J. Kacuba, M. A. Crowe, S. T. Butler, and M. C. Wiltbank. 2012. Presynchronization with Double-Ovsynch improves fertility at first postpartum artificial insemination in lactating dairy cows. J. Dairy Sci. 95:7003-7014. https://doi.org/10.3168/jds.2011-5260.

Holman, A., J. Thompson, J. E. Routly, J. Cameron, D. N. Jones, D. Grove-White, R. F. Smith, and H. Dobson. 2011. Comparison of oestrus detection methods in dairy cattle. Vet. Rec. 169:47. https://doi.org/10.1136/vr.d2344.

Iwersen, M., U. Falkenberg, R. Voigtsberger, D. Forderung, and W. Heuwieser. 2009. Evaluation of an electronic cowside test to detect subclinical ketosis in dairy cows. J. Dairy Sci. 92:2618-2624. https://doi.org/10.3168/jds.2008-1795.

Jordan, E. R., M. J. Schouten, J. W. Quast, A. P. Belschner, and M. A. Tomaszewski. 2002. Comparison of two timed artificial insemination (TAI) protocols for management of first insemination postpartum. J. Dairy Sci. 85:1002-1008. https://doi.org/10.3168/ jds.S0022-0302(02)74160-X.

Kiddy, C. A. 1977. Variation in physical activity as an indication of estrus in dairy cows. J. Dairy Sci. 60:235-243. https://doi.org/10 .3168/jds.S0022-0302(77)83859-9.

Lopez, H., L. D. Satter, and M. C. Wiltbank. 2004. Relationship between level of milk production and estrous behavior of lactating dairy cows. Anim. Reprod. Sci. 81:209-223. https://doi.org/10 .1016/j.anireprosci.2003.10.009. 
Løvendahl, P., and M. G. Chagunda. 2010. On the use of physical activity monitoring for estrus detection in dairy cows. J. Dairy Sci 93:249-259. https://doi.org/10.3168/jds.2008-1721.

Madureira, A. M., B. F. Silper, T. A. Burnett, L. Polsky, L. H. Cruppe, D. M. Veira, J. L. Vasconcelos, and R. L. Cerri. 2015. Factors affecting expression of estrus measured by activity monitors and conception risk of lactating dairy cows. J. Dairy Sci. 98:7003-7014. https://doi.org/10.3168/jds.2015-9672.

Maldonado, G., and S. Greenland. 1993. Simulation study of confounder-selection strategies. Am. J. Epidemiol. 138:923-936.

McDougall, S., R. Macaulay, and C. Compton. 2007. Association between endometritis diagnosis using a novel intravaginal device and reproductive performance in dairy cattle. Anim. Reprod. Sci. 99:923. https://doi.org/10.1016/j.anireprosci.2006.03.017.

Neves, R. C., K. E. Leslie, J. S. Walton, and S. J. Leblanc. 2012 Reproductive performance with an automated activity monitoring system versus a synchronized breeding program. J. Dairy Sci. 95:5683-5693. https://doi.org/10.3168/jds.2011-5264.

Remnant, J. G., M. J. Green, J. N. Huxley, and C. D. Hudson. 2015. Variation in the interservice intervals of dairy cows in the United Kingdom. J. Dairy Sci. 98:889-897. https://doi.org/10.3168/jds .2014-8366

Risco, C., and P. Melendez. 2011. Dairy Production Medicine. 1st ed. Wiley-Blackwell, Oxford, UK. https://doi.org/10.1002/ 9780470960554

Sartori, R., J. M. Haughian, R. D. Shaver, G. J. Rosa, and M. C. Wiltbank. 2004. Comparison of ovarian function and circulating steroids in estrous cycles of Holstein heifers and lactating cows. J. Dairy Sci. 87:905-920. https://doi.org/10.3168/jds.S0022 -0302(04)73235-X.
Souza, A. H., H. Ayres, R. M. Ferreira, and M. C. Wiltbank. 2008. A new presynchronization system (Double-Ovsynch) increases fertility at first postpartum timed AI in lactating dairy cows. Theriogenology 70:208-215. https://doi.org/10.1016/j.theriogenology .2008.03.014.

Stevenson, J. S., and A. P. Phatak. 2005. Inseminations at estrus induced by presynchronization before application of synchronized estrus and ovulation. J. Dairy Sci. 88:399-405. https://doi.org/10 .3168/jds.S0022-0302(05)72700-4.

Tenhagen, B.-A., M. Drillich, R. Surholt, and W. Heuwieser. 2004. Comparison of timed AI after synchronized ovulation to ai at estrus: Reproductive and economic considerations. J. Dairy Sci 87:85-94. https://doi.org/10.3168/jds.S0022-0302(04)73145-8.

Valenza, A., J. O. Giordano, G. Lopes Jr., L. Vincenti, M. C. Amundson, and P. M. Fricke. 2012. Assessment of an accelerometer system for detection of estrus and treatment with gonadotropin-releasing hormone at the time of insemination in lactating dairy cows. J. Dairy Sci. 95:7115-7127. https://doi.org/10.3168/jds.2012-5639.

Walsh, R. B., D. F. Kelton, T. F. Duffield, K. E. Leslie, J. S. Walton, and S. J. LeBlanc. 2007. Prevalence and risk factors for postpartum anovulatory condition in dairy cows. J. Dairy Sci. 90:315-324. https://doi.org/10.3168/jds.S0022-0302(07)72632-2.

Wiltbank, M. C., G. M. Baez, F. Cochrane, R. V. Barletta, C. R. Trayford, and R. T. Joseph. 2015. Effect of a second treatment with prostaglandin F2 $\alpha$ during the Ovsynch protocol on luteolysis and pregnancy in dairy cows. J. Dairy Sci. 98:8644-8654. https:// doi.org/10.3168/jds.2015-9353. 